\title{
A case of giant cell myocarditis: Bridge to recovery by long-term mechanical circulatory support without immunosuppressive therapy
}

\author{
Toshifumi Murashita, MD, PhD, Takashi Sugiki, MD, Tsuyoshi Tachibana, MD, PhD, Takashi Kunihara, MD, PhD,
} and Hiroshi Sugiki, MD, Sapporo, Japan

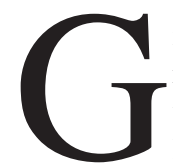
iant cell myocarditis (GCM) is an uncommon and rapidly fatal disorder resulting in cardiac transplantation or death. ${ }^{1}$ Immunosuppressive therapy could prolong the average transplant-free survival period of patients GCM. The ventricular-assist device (VAD) usually provides support during the period of assessment of transplant candidacy, and there is only 1 reported case of a bridge to recovery with immunosuppression. ${ }^{2}$ We report the unusual case of a young patient with cardiogenic shock caused by GCM who recovered after 7 months of left ventricular assistance without immunosuppressive therapy.

\section{Clinical Summary}

A 28-year-old woman $(158 \mathrm{~cm}, 39 \mathrm{~kg})$ had been experiencing progressive symptoms, including fatigue and dyspnea. An electrocardiogram showed complete heart block, and an echocardiogram showed a left ventricular ejection fraction (LVEF) of 0.17 with a dilated left ventricle. Despite support with intra-aortic balloon pumping and percutaneous cardiopulmonary support, the lack of improvement of left ventricular function led to the need for a left VAD. The left VAD (Toyobo VAD; Toyobo Ltd, Osaka, Japan) was placed by using a cannula with a graft extension sewn onto the aorta as the outflow line, while the inflow line was inserted through the left ventricular apex and the muscle excised from the apex was sent for examination. Histologic examination (Figure 1) indicated GCM.

After the operation, maximum inotropic support was required because of right ventricular failure. Although the literature suggests a beneficial effect of immunosuppression for GCM, this was kept in reserve because of possible infection in the situation of left VAD implantation. A right ventricular catheter biopsy carried out on the 62nd postoperative day showed a mixed inflammatory infiltrate without giant cells. During this period, brain natriuretic peptide was decreased from $1176 \mathrm{pg} / \mathrm{mL}$ to $232 \mathrm{pg} / \mathrm{mL}$, whereas echocardiography showed improved left ventricular function with LVEF of 0.25 . Carvedilol, a $\beta$-blocker, was commenced and increased stepwise, during which time brain natriuretic peptide was further decreased to $48 \mathrm{pg} / \mathrm{mL}$. Repeated right ventricular

From the Department of Cardiovascular Surgery, Hokkaido University Hospital, Sapporo, Japan.

Received for publication Nov 27, 2005; accepted for publication April 25, 2006.

Address for reprints: Toshifumi Murashita, MD, PhD, Department of Cardiovascular Surgery, Hokkaido University Hospital, Kita-14, Nishi-5, Kita-ku, Sapporo 060-8648, Japan (E-mail: muratosh@med.hokudai.ac.jp).

J Thorac Cardiovasc Surg 2006;132:432-3

$0022-5223 / \$ 32.00$

Copyright (C) 2006 by The American Association for Thoracic Surgery

doi:10.1016/j.jtcvs.2006.04.022 biopsy showed fewer inflammatory cells and increased fibrosis but no giant cells, whereas left ventricular function was further improved with LVEF of 0.45 in a left VAD off test. The patient was successfully weaned from the left VAD on the 222nd postoperative day. The patient's condition has been good without immunosuppression for 1 year. Recent echocardiography revealed LVEF of 0.47. The patient is in New York Heart Association functional class I, and she has returned to normal life.

\section{Discussion}

A report that analyzed data in the Multicenter Giant Cell Myocarditis Registry found ventricular assistance to be an effective bridge to transplantation for patients with GCM-induced heart failure. ${ }^{3}$ The success rate of bridging patients with GCM to transplantation with a VAD, 78\%, is similar to that with other VAD bridges; however, no patient was weaned from the VAD. Another recent study suggests that the average transplant-free survival period of patients with GCM treated with immunosuppression is more than 4 times longer than that of patients who receive no immunosuppressive therapy. There was 1 reported case of a bridge to recovery for GCM; in that case, the recovery with immunosuppression was sufficient to obviate the need for heart transplantation, and the patient was weaned from the VAD after 10 days of assistance. ${ }^{2}$

Acute myocarditis caused by GCM is rare, not all patients undergo endomyocardial biopsy for histologic diagnosis, and the timing of the biopsy varies. Because the diagnosis of GCM can be made when histologic findings are confirmed, regardless of the timing of the biopsy, the incidence of GCM among patients with myocarditis is uncertain. In our case, diagnosis of GCM was made with left ventricular muscle taken from the left ventricular apex in the acute phase, whereas the postoperative repeated endomyocardial biopsy was performed on the right ventricle, which may differ from the left. Because the complex inflammatory and healing processes are difficult to characterize with a snapshot of tissue pathology, serial endomyocardial biopsies are required. ${ }^{4}$

Another group 5 reported a patient with GCM who had been in cardiogenic shock but recovered completely after conventional immunosuppression. They inferred that GCM is a heterogeneous disease, with one form that can recover with immunosuppressive therapy and another form that cannot recover and requires cardiac transplantation. Because it is detected earlier, a rapidly progressive acute inflammatory disease may be less damaging than a slowly progressive one, provided that circulatory support is begun in time. It is quite possible that chronic inflammatory changes greatly reduce the potential for recovery from a slowly progressive disease. One may hypothesize from this case that GCM is a heterogeneous disease with one form that can recover without immunosuppression and other forms that respond to immunosuppressive therapy or require cardiac transplantation. 

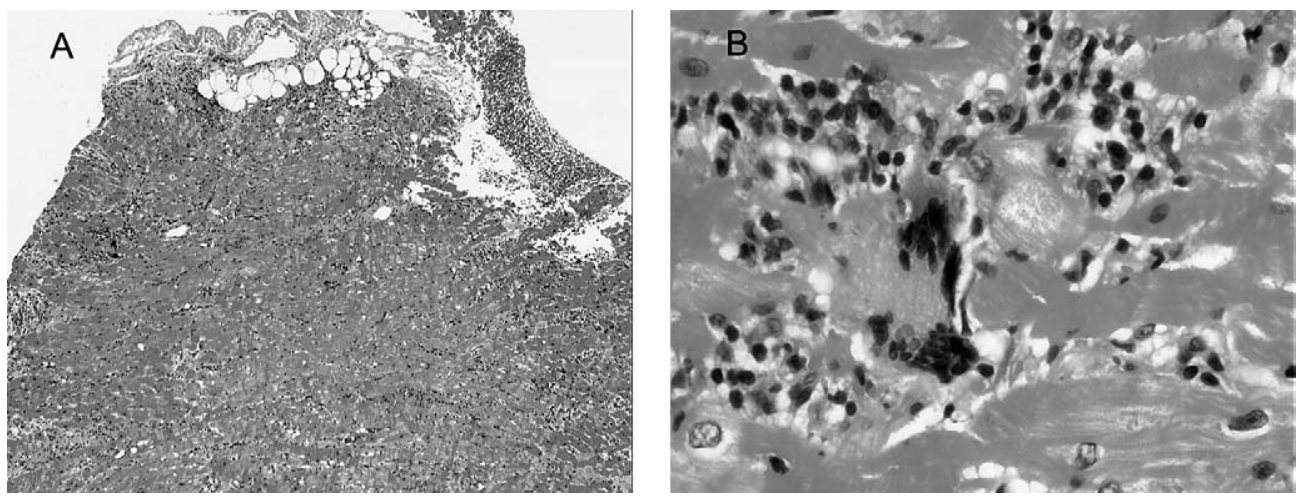

Figure 1. A, Histologic examination showing widespread or multifocal serpiginous necrosis with multinucleated giant cells and mixed inflammatory infiltrate composed of lymphocytes and few eosinophils. B, Multinucleated giant cells seen adjacent to necrosis.

\section{References}

1. Cooper LT Jr, Berry GJ, Shabetai R. Idiopathic giant-cell myocarditisnatural history and treatment. Multicenter Giant Cell Myocarditis Study Group Investigators. N Engl J Med. 1997;336:1860-6.

2. Marelli D, Kermani R, Bresson J, Fishbein MC, Hamilton M, Moriguchi J, et al. Support with the BVS 5000 assist device during treatment of acute giant-cell myocarditis. Tex Heart Inst J. 2003;30:50-6.
3. Brilakis ES, Olson LJ, Berry GJ, Daly RC, Loisance D, Zucker M, et al. Survival outcomes of patients with giant cell myocarditis bridged by ventricular assist devices. ASAIO J. 2000;46:569-72.

4. Stoica SC, Goddard M, Tsui S, Dunning J, McNeil K, Parameshwar J, et al. Ventricular assist surprise: giant cell myocarditis or sarcoidosis? J Thorac Cardiovasc Surg. 2003;126:2072-4.

5. Frustaci A, Chimenti C, Pieroni M, Gentiloni N. Giant cell myocarditis responding to immunosuppressive therapy. Chest. 2000;117:905-7.

\section{Ascending-descending aortic bypass with the aid of a heart-lifting device}

Alejandro Aris, MD, PhD, ${ }^{a}$ Javier Cobiella, MD, ${ }^{a}$ Maria Luz Maestre, MD, ${ }^{\mathrm{b}}$ and Maria Teresa Subirana, MD, ${ }^{\mathrm{C}}$ Barcelona, Spain

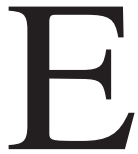
xtra-anatomic aortic bypass from the ascending to the descending aorta is an alternative for repair of complex aortic anomalies. We describe a case of repair of recoarctation of the aorta through a median sternotomy and posterior pericardial approach in which surgical exposure of the

From the Departments of Cardiac Surgery, ${ }^{\mathrm{a}}$ Anesthesia, ${ }^{\mathrm{b}}$ and Cardiology, Hospital de la Santa Creu i Sant Pau, Barcelona, Spain.

Received for publication April 7, 2006; accepted for publication April 20, 2006.

Address for reprints: Alejandro Aris, MD, PhD, Department of Cardiac Surgery, Hospital de la Santa Creu i Sant Pau, Avenida San A. M. Claret 167, 08025 Barcelona, Spain (E-mail: aaris@santpau.es).

J Thorac Cardiovasc Surg 2006;132:433-4

$0022-5223 / \$ 32.00$

Copyright $\odot 2006$ by The American Association for Thoracic Surgery doi:10.1016/j.jtcvs.2006.04.017 retrocardiac aorta was obtained by means of a heartlifting device (Starfish 2; Medtronic, Inc, Minneapolis, Minn) commonly used in off-pump coronary artery bypass grafting.

\section{Clinical Summary}

A 70-year-old man was seen with dyspnea on exertion and intermittent claudication. He was hypertensive, in atrial fibrillation, and taking oral anticoagulants. His medical history included repair of aortic coarctation (end-to-end anastomosis) 29 years previously. Echocardiography showed left ventricular hypertrophy with moderately depressed left ventricular function (ejection fraction 40\%). He underwent aortic angiography, which confirmed the diagnosis of aortic recoarctation with a gradient of $48 \mathrm{~mm} \mathrm{Hg}$ across the coarctation. The thoracic descending aorta was tortuous (Figure 1).

In view of the patient's age and left ventricular impairment, it was decided that an extra-anatomic repair would be less harmful 